
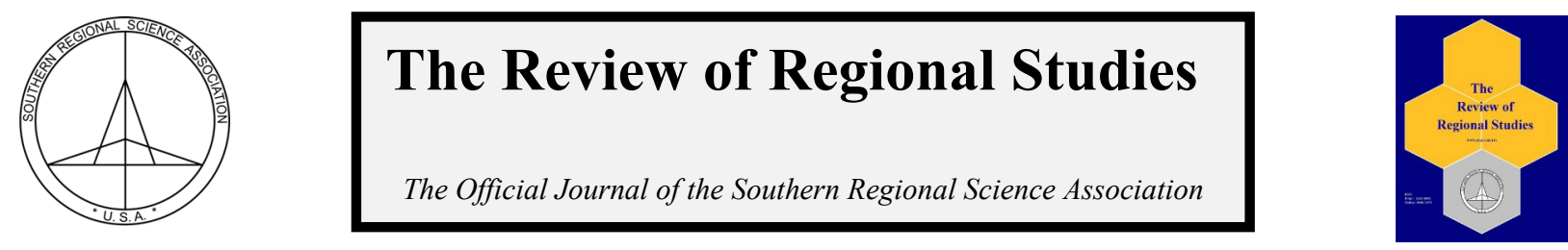

\title{
Does Private Schooling Increase Adult Earnings? Cohort-Level Evidence for U.S. States*
}

\author{
Reilee L. Berger ${ }^{\mathrm{a}}$ and John V. Winters ${ }^{\mathrm{a}}$ \\ ${ }^{a}$ Department of Economics and Legal Studies, Oklahoma State University, USA
}

\begin{abstract}
Public schooling in the U.S. has numerous critics, many of whom suggest that alternatives such as providing vouchers for private schools may be more effective. This paper combines decennial census and American Community Survey data for various years to examine the relationship between cohort-level private-schooling rates and later earnings during adulthood. We also explore differences by sex and examine the role played by the quantity of education completed and occupational attainment. We find a significant positive relationship between privateschooling rates and adult earnings for women but a small relationship for men.
\end{abstract}

Keywords: private schooling, school choice, K-12 education, earnings, wages

JEL Codes: I20, J24, R50

\section{INTRODUCTION}

The effectiveness of public schools has been questioned in recent years in numerous dimensions, and many stakeholders claim that the American public educational system is deeply flawed. ${ }^{1}$ Private schooling does provide an alternative, but it is costly for individuals and currently inaccessible to many with limited means. Furthermore, there is no consensus among researchers as to the benefits from private schools. There is, however, some evidence to suggest that attending a private school might provide an individual with various benefits later in life. Catholic schools, in particular, seem to provide greater long-run benefits than do public schools (Neal, 1998). Different explanations from various authors have been offered to explain the possible advantages of private schooling. Some argue that the quality of the school in general matters, while others suggest that teacher value makes the difference. ${ }^{2}$ School quality differs in

\footnotetext{
* We thank the Editors, three anonymous reviewers, seminar participants at Oklahoma State University and conference participants at the Missouri Valley Economic Association 52nd Annual Meeting for helpful comments.

Berger completed a Bachelor of Science in Quantitative Economics in 2016 at Oklahoma State University, Stillwater, OK 740784011. Winters is an Associate Professor in the Department of Economics and Legal Studies at Oklahoma State University, Stillwater, OK 74078-4011. Corresponding Author: J.V. Winters E-mail: jvwinte@okstate.edu

${ }^{1}$ This is disputed by others. For example, Bracey (1996) claimed that even though American students rank lower in standardized tests than students in many developed nations, these rankings are often overstated and have small marginal differences. Peltzman (1993) added that while there was a significant and indisputable decline in academic performance in the 1960s and 1970s, since then test scores have increased for American students. However, the bulk of the dialogue surrounding American public schools suggests that major reform is needed.

${ }^{2}$ For example, Card and Krueger (1992) found that school quality in general has a significant impact on future wages. They discovered that men who attended schools in states with higher quality schools received higher wages. Chetty, Friedman, and Rockoff (2014) found that students with higher value added teachers earn more income. The value added measurement shows a teacher's impact on student academic achievement. Replacing a bottom 5\% value added teacher with an average teacher would increase a student's lifetime earnings by $\$ 250,000$.
}

(c) Southern Regional Science Association 2016.

ISSN 1553-0892, 0048-749X (online)

www.srsa.org/rrs 
numerous dimensions including resource-based gaps such as student-teacher ratios, physical structures, equipment and materials used, and the ability to attract and retain high-quality teachers. Also, it is possible that the environment created within the school has a significant impact, possibly due to administrative leadership, teacher motivation, student motivation, and peer quality.

Many policymakers and advocates claim education reform is a national priority, but there is wide disagreement on the appropriate direction. Some argue that the failures of the public education system are primarily due to insufficient resources and that increased public spending on education is the appropriate reform. ${ }^{3}$ Others suggest that the main problem is not a lack of resources but how those resources are allocated and managed. Specifically, the latter camp argues that increased use of market mechanisms in education would promote competition and innovation to improve education outcomes. Suggested market reforms include increased use of student vouchers to attend private schools, charter schools, school choice programs allowing students to attend public schools outside their residential zone/district, and performance-based compensation for teachers and principals.

Our analysis does not address the efficacy of any particular market reforms, but rather seeks to provide additional information regarding the impact of public and private education, primarily by focusing on earnings. If alternatives to traditional public schooling offer higher quality education, the benefits should show up as higher earnings. We exploit cohort-level variation in private-schooling rates among young people in the 1980 and 1990 decennial censuses. We then match these cohort-level private-schooling rates to adults in the 2006-2013 American Community Survey (ACS) to examine the effects of private schooling on adult earnings. We examine differences by sex and explore relationships with years of schooling and occupational attainment. We find a significant positive relationship between private-schooling rates and adult earnings for women but not for men.

\section{PREVIOUS LITERATURE}

Existing research suggests that there are considerable differences in school quality both across areas and across schools within areas. Furthermore, private schooling and market-based reforms have potential to improve educational outcomes. ${ }^{4}$ Early research on this topic used the 1980 High School and Beyond (HS\&B) dataset produced by the National Center for Education Statistics (NCES) to examine the effects on student test scores. HS\&B randomly selected schools and analyzed a sophomore and senior cohort every two years from 1980-1986. Coleman, Hoffer, and Kilgore (1982) analyzed the first cohorts of HS\&B and found that students enrolled in private schools perform better in mathematics and vocabulary than public school students. Evans and Schwab (1995) supported their findings, and added that students attending Catholic schools are 13 percent more likely to graduate high school or attend a university. But Witte (1992) concluded from HS\&B that any statistically significant private-school advantage was negligible in size.

\footnotetext{
${ }^{3}$ For example, increased education spending and higher teacher salaries have been shown to increase educational performance (Cebula, Mixon, and Montez, 2015; Jackson, Johnson, and Persico, 2016).

${ }^{4}$ The discussion herein focuses on effects of private schools but other market-based reforms have been examined as well. For example, Dobbie and Fryer (2013) examined charter schools in New York and found that students who won a lottery to attend a charter school outperformed lottery losers in public schools on math and reading tests. Similarly, Sass et al. (2016) found that charter schools increase a student's likelihood of graduating high school and college and provide higher earnings potential.
}

(C) Southern Regional Science Association 2016. 
Rouse (1998) examined the effectiveness of private-school vouchers in Milwaukee and found that students' math scores increased due to the voucher system. Peterson and Llaudet (2006) used another NCES dataset, the National Assessment of Educational Progress (NAEP) to examine the academic achievement of fourth and eighth grade students in math and reading. In both grades and in both categories, private-school students showed an advantage (with conflicting results for fourth grade math, however). Catholic schools were noted to perform particularly well in their analysis. More recently, Coughlin and Castilla (2014) found that private high school students are more likely to graduate college. They claimed that private schools achieve this by better preparing their students to start college. Duncan and Sandy (2007) also noticed heterogeneous results of public and private schooling on student test scores but indicated that the average gap between public and private students is primarily due to family background.

Private schooling has also been shown to increase earnings later in life. Sandy and Duncan (1996) used National Longitudinal Survey of Youth (NLSY) data to show that private high school graduates earn more in their careers. They suggested that private high schools are on average higher in quality than public schools. They did note, however, that families and students' attitudes toward schools could have something to do with the results. Gritsch (2006) examined NLSY data and agreed that private-school students do go on to earn higher wages than do public school students. But, due to the cost of tuition, the paper finds that private rates of return vary among schools, with no clear advantage to public or private.

Some researchers have focused on the benefits of Catholic private schools in particular because they make up a large portion of all private schools. Being religiously Catholic has also been used to instrument for private/Catholic school attendance (Evans and Schwab, 1995; Neal, 1997; Vella, 1999; Kim, 2011). ${ }^{5}$ Neal (1997) examined high school and college graduation rates, as well as future income for private and public school students. He found that in urban areas, private schools had a significant positive impact on all three outcomes. But in suburban and mostly white areas, the advantage was slight or insignificant. Kim (2011) found that Catholic school students can expect higher wages throughout their careers and that the increase can be explained by the quality of the school, teacher, and math courses taken. Vella (1999) found that private-school attendees in Australia are 17 percent more likely to graduate high school and also more likely to attend college. Also for Australia, Jha and Polidano (2015) found that long-term income was higher for private-school graduates than public school graduates.

Another reason private schools seem to provide higher earnings for graduates could be the characteristics of Catholic schools, which make up a large portion of private schools. Lee et al. (1998) noted that private-school students take more advanced math classes than public school students, with especially strong effects for Catholic schools, and that advanced math courses may lead to better college preparation and higher earnings. Coleman and Hoffer (1987) offered that Catholic schools have an environment more conducive to learning. This is because the values of the community are shared with the values of the school, which they claim are vital to academic achievement. They state that public and other non-Catholic private schools do not offer the same continuity between community and school. Coleman and Hoffer (1987) argue that Catholic schools are especially effective at creating and leveraging social capital to improve student outcomes. This may increase the depth, breadth, and quality of social ties to student peers, their parents, and other community members. Stronger social capital likely translates into better labor

\footnotetext{
${ }^{5}$ See Neal (1998) for a detailed review of the early literature.
}

(C) Southern Regional Science Association 2016. 
market outcomes later in life. Thus, private schooling effects on social networks may be an important source of private schooling benefits. ${ }^{6}$

Still, there is no clear consensus in the literature on the effects of private schools in general or Catholic schools in particular. Altonji, Elder, and Taber (2005) conclude that being religiously Catholic is not an exogenous instrument for examining the effects of Catholic schooling and call into question the accuracy of other studies using this instrumental variables strategy. Similarly, Elder and Jepsen (2014) find that the test score advantage for U.S. Catholic school students is entirely due to selection bias. We adopt a novel approach using cohort-level data, and our results are not affected by unobserved individual characteristics or selection effects that only vary across students within state-year cohorts and average out across cohorts. There are some potential limitations to our approach discussed below, which we believe sheds additional light on the potential benefits of private schooling.

\section{DATA AND EMPIRICAL APPROACH}

This paper combines data from the U.S. decennial census and the American Community Survey (ACS) for various years to examine the effects of cohort-level private-schooling rates on earnings later in life. All data are obtained from IPUMS (Ruggles et al., 2015). The data do not provide individual information on past public or private schooling for adults who are no longer in school. Still, we can observe public versus private schooling decisions for young people while they are in school. We use the private-schooling information for young people in the 1980 and 1990 decennial census 5 percent IPUMS files to construct state and year-of-birth cohort-level average private-schooling rates. ${ }^{7}$ We then match these at the birth-state and birth-year cohortlevel to adult earnings information from the 2006-2013 ACS. A similar cohort-level approach is used by Winters (2015) to examine the income returns to additional years of schooling.

Because of data limitations, we limit the sample to non-Hispanic whites. Both earnings outcomes and private-schooling rates can differ considerably across race and ethnicity. We prefer to avoid relying on cohort-level variation driven by racial and ethnic compositional differences since unobservable factors could be important concerns.

We experimented by conducting separate analyses for minorities, but small sample sizes in some states and potential compositional differences across cohorts encouraged us to defer this to future research. Limiting the sample to non-Hispanic whites allowed us to focus on a relatively homogenous group to better discern the effects of private-schooling rates on adult earnings outcomes. Because we measured earnings in logs, our sample also excludes persons with non-positive earnings; for consistency we extend this sample exclusion criteria to all outcomes that we consider.

We estimate variants of the following linear regression model:

$$
\text { (1) } Y_{\text {iscta }}=\alpha+\beta \text { PrivSchoolRate }_{s c}+\gamma \text { StateControls }_{s c}+\delta_{s}+\varphi_{c}+\theta_{t}+\pi_{a}+\varepsilon_{i s c t a}
$$

\footnotetext{
${ }^{6}$ Unfortunately, our data are not conducive to exploring social networks from private schooling as a particular mechanism. This could be a fruitful area for future research using different data.

${ }^{7}$ Some private schools specialize in educating children with physical, mental, and emotional difficulties. There is some concern that this could adversely affect our analysis. However, Greene and Winters (2007) indicate that only 1.48 percent of students with disabilities receive public funding to attend private schools and this constitutes less than 0.2 percent of total student enrollment in public and private schools. Of course, parents of students with disabilities can self-fund private schooling, but financial constraints make this unlikely to be sufficiently widespread to affect our private schooling measure in a meaningful way. Furthermore, our ACS analysis below excludes persons not in the workforce, thereby excluding those with severe disabilities.
} 
where $Y_{\text {iscta }}$ is an adult outcome observed in the ACS such as log annual earnings (or a related measure discussed below) for individual $i$ born in state $s$, and year-of-birth cohort $c$ observed during survey year $t$ at age $a$. The key explanatory variable, PrivSchoolRate Prc $_{s c}$, is the privateschooling rate for year-of-birth cohort $c$ born in state $s .{ }^{8}$ The private-schooling rate is measured for cohorts ages 8-17 in the 1980 and 1990 censuses. It is computed as the ratio of the number of persons enrolled in private school relative to the total number of persons enrolled in public or private school, ${ }^{9}$ with both the numerator and denominator of the ratio specific to the state-year cohort. For example, suppose the state of Alabama in 1990 contains 44,000 persons age 15 enrolled in public school and 6,000 persons age 15 enrolled in private school. The privateschooling rate for this cohort would then equal 6,000 divided by 50,000 or 0.12 and indicate that 12 percent of students in the cohort are enrolled in private school.

We define the year of birth as the survey year minus age at the time of the survey. Thus, persons ages 8-17 in the 1980 census are assumed to have been born between 1963 and 1972 . Persons ages 8-17 in the 1990 census are assumed to have been born between 1973 and 1982 . Thus, we have 20 years of cohorts. ${ }^{10}$ We also observe birth cohorts for each of the 50 states giving us 1,000 unique state and year-of-birth cohorts. We exclude persons born in the District of Columbia and persons born outside the U.S.

The regression equation also includes a number of control variables. StateControls $s_{S C}$ includes four state and year-of-birth cohort-level controls computed from the 1980 and 1990 censuses in a similar manner to the private-schooling rate; these include average household income, average maternal years of schooling, average paternal years of schooling, and average number of siblings. Higher parental earnings and schooling levels likely induce both higher private-schooling rates and, later, enhanced adult earnings; thus, they should be included as controls to avoid omitted variable bias. The number of siblings could also affect private schooling and adult outcomes. We also include a state control for the 2006-2013 ACS cohort share of observations with nonpositive earnings to account for possible selection effects into the labor market from limiting the sample to those with positive earnings. Other factors besides schooling may affect supply and demand for labor across cohorts pushing marginally attached individuals into or out of the labor force. These marginally attached participants may have lower productivity and experience below-average earnings when employed. Controlling for the cohort share with nonpositive earnings is a cohort-level analog to predicting and controlling for the individual probability of having earnings and being in the sample but it is much more practically estimated for our model with a large number of fixed effects.

The regression equation also includes birth-state fixed effects $\left(\delta_{s}\right)$ to account for timeinvariant differences across states; their inclusion means that the identifying variation in privateschooling rates comes from differences across cohorts within states. Fixed effects for year of birth $\left(\varphi_{c}\right)$, survey year $\left(\theta_{t}\right)$, and age $\left(\pi_{a}\right)$ at the time of the ACS are also included to account for potential aggregate differences across time and age. In our full specifications discussed below,

\footnotetext{
${ }^{8}$ Birth state is the only historical geographic variable, which is included in both the decennial censuses and the ACS, that allows us to link cohorts across survey years.

${ }^{9}$ For most cohorts, nearly $100 \%$ of young people are enrolled in school, but a few people are not in school, especially among older cohorts, e.g., ages 16 and 17, who can legally drop out of school in many states. Restricting the analyses below to persons who were ages 8-15 in 1980 or 1990 does not qualitatively alter the results.

10 These cohorts are ages 24-50 during the 2006-2013 ACS. The 1980 and 1990 Census surveys are intended to measure age as of April 1 of the census year, but the ACS age is based on the date of the survey, which is conducted throughout the year. This inconsistency introduces some measurement error, but hopefully its effects on our analysis are minimal.
}

(C) Southern Regional Science Association 2016. 
we also control for birth-state-specific linear time trends for year of birth, in which identifying variation comes from differences across cohorts within states that deviate from the state's linear time trend. Regression standard errors reported below are clustered by birth state to account for possible serial correlation within birth states. We use Stata MP 13.0 with the reghdfe command, which is a computationally practical way to absorb a large number of fixed effects and statespecific trends. All regressions use survey weights provided by the ACS.

We examine four adult outcomes from the 2006-2013 ACS as dependent variables. The first outcome is the log of annual earnings, which is directly reported by survey respondents. The second is the log of hourly earnings. Hourly earnings are computed by dividing annual earnings by estimated annual hours worked. The ACS directly reports the usual number of hours that individuals worked per week, but the number of weeks worked in the previous year is reported only in intervals for years 2008-2013. We use available information on actual weeks worked in the 2006-2007 ACS (available as an integer variable from 1 to 52) to estimate mean weeks worked for the weeks worked intervals. We then multiply estimated weeks worked by usual hours worked to compute estimated annual hours worked. Log hourly earnings should be closely correlated with log annual earnings but it attempts to control for differences in the quantity of labor supplied to more precisely measure the price per unit of labor that workers receive.

Our third dependent variable is simply a measure of the years of schooling completed. ${ }^{11}$ The ACS reports education levels based on the highest credential completed. We convert these to years of schooling based on the usual time required, e.g., a high school diploma is defined as 12 years of schooling and a bachelor's degree is defined as 16 years of schooling. Our fourth measure is an occupation earnings score constructed by IPUMS; see the variable ERSCOR90. The variable uses 1990 occupation scheme definitions to compute median earned income for each occupation. To facilitate comparability over time, ERSCOR90 is converted to percentile rankings and hence takes on values between 0 and 100 with higher values indicating higher earning occupations. The third and fourth outcomes will help assess the role of schooling and occupational attainment as possible mechanisms by which private schooling might affect adult earnings.

Effects of private schooling on adult outcomes could vary by sex for various reasons discussed below. Therefore, we estimate the regression equations separately for women and men. In doing so, we also measure the cohort schooling rates to be sex-specific since parental decisions for private schooling may depend on the child's sex. Similarly, employment rates differ by sex, so we measure the share with non-positive earnings to be sex-specific. But we do not measure the other state control variables to be sex-specific since parental education, income, etc. are more likely to be invariant to their child's sex. As a practical matter, using sex-specific controls does not meaningfully alter the results.

Our identification strategy relies on sex-specific, cohort-level variation in privateschooling rates to examine the effects of private schooling on later adult outcomes. This is a novel approach in the literature with various strengths and weaknesses. Since private schooling is not observed at the individual level for our adult outcomes sample, a major strength is that our results are not affected by unobserved individual characteristics or selection effects across students within state-year cohorts that average out across cohorts. But average differences across

\footnotetext{
11 To maintain comparability with the earnings results, the samples for our third and fourth outcomes are also restricted to persons with positive earnings.
}

(C) Southern Regional Science Association 2016. 
cohorts in unobservable characteristics or other omitted variables are potentially problematic if correlated with private-schooling rate differences across cohorts. ${ }^{12}$ Unfortunately, we are unable to isolate the factors driving the variation in private-schooling rates across cohorts within states. Still, we suggest that including our detailed set of control variables leaves remaining variation in private-schooling rates that is likely to be largely random and give accurate results.

Summary statistics are reported in Table 1 separately for females and males. Like our regressions, these use ACS individual survey weights and thus give greater weight to larger states and larger cohorts within states. Exponentiating the mean log earnings implies annual earnings of about $\$ 26,000$ for women and $\$ 42,000$ for men. Women on average work fewer hours, so the log hourly earnings gap by sex is smaller but still large and more than 20 percent. Women have higher average years of schooling but lower average occupational earnings scores. The private-school enrollment rate for both females and males is about 11 percent, although slightly higher for females.

Table 1: Summary Statistics

\begin{tabular}{lrrrr}
\hline \hline & \multicolumn{2}{c}{ Females } & \multicolumn{2}{c}{ Males } \\
& Mean & Std. Dev. & Mean & Std. Dev. \\
\hline Dependent Variables & & & & \\
Log Annual Earnings & 10.169 & 1.116 & 10.657 & 1.000 \\
Log Hourly Earnings & 2.852 & 0.755 & 3.078 & 0.770 \\
Years of School & 14.298 & 2.389 & 13.874 & 2.449 \\
Occupational Earnings Score (Percentile) & 50.459 & 48.885 & 68.856 & 111.708 \\
& & & & \\
Main Explanatory Variables & & & & \\
Cohort Private-school Enrollment Rate & & & & \\
& & & & \\
Control Variables & & & & \\
Cohort Log Average Parental Household Income & 11.012 & 0.128 & 11.012 & 0.128 \\
Cohort Average Mom Years of School & 12.153 & 0.831 & 12.156 & 0.830 \\
Cohort Average Dad Years of School & 12.499 & 0.963 & 12.505 & 0.962 \\
Cohort Average Number of Siblings & 1.560 & 0.254 & 1.560 & 0.258 \\
Cohort Share with Nonpositive Earnings & 0.197 & 0.035 & 0.091 & 0.022 \\
Age & 37.3 & 6.4 & 37.3 & 6.3 \\
Survey Year & 2009.4 & 2.3 & 2009.4 & 2.3 \\
Birth Year & 1972.1 & 5.9 & 1972.2 & 5.9 \\
\hline \hline
\end{tabular}

Notes: The sample includes non-Hispanic whites born in the U.S. during years 1963-1982. The dependent variables, age, survey year, and cohort share with non-positive earnings controls, are from the 2006-2013 American Community Survey. The cohort private-schooling rates and all other cohort control variables are computed from the 1980 and 1990 decennial census 5 percent PUMS. The 2006-2013 ACS analytical sample is also limited to workers with positive earnings and includes 1,539,809 individual observations for females and 1,710,699 individual observations for males.

\footnotetext{
12 We also cannot rule out externalities or separate them from direct effects, but we believe that the direct effects should be first order and spillover effects second order, so any resulting bias is hopefully minimal.
}

(C) Southern Regional Science Association 2016. 


\section{EMPIRICAL RESULTS}

Tables 2-5 show the coefficients and standard errors for females and males for the four different outcomes. For each table we present three specifications. The first column excludes time-varying birth-state controls; the second adds the birth-state controls; and the third also adds birth-state-specific time trends. We only present results for the private-schooling explanatory variables; results for the time-varying state control variables are available by request from the corresponding author.

In Table 2, we see that female adult log annual earnings are significantly affected by private-schooling rates at the five percent level in columns 1-3. The dependent variable in Table 2 (and 3) is measured in logs and the private-schooling rate is measured as a share ranging from zero to one, so the coefficients can be approximately interpreted as percentage increases in the dependent variable that would result from an increase in private-school enrollment rates from 0 to 100 percent. While such an increase in private-school enrollment is not observed in the data and not generally possible, the scaling is helpful for interpreting the economic importance of the marginal effects. It also increases comparability with previous studies using individual level data that estimate the effect of a binary change from public to private schooling. The coefficient of 0.230 for females in column 1 of Table 2 means that going from 0 to 100 percent private-school enrollment would equate to an approximate increase in annual earnings of 23 percent for that cohort. This is an economically meaningful effect, and the coefficient estimates in columns 2 and 3 of 0.239 and 0.275 are even slightly larger. But for males, we observe statistically insignificant effects on annual earnings with small negative coefficient estimates.

Table 3 reports results for the log of hourly earnings. The female coefficient across the three specifications is now 0.187, 0.185, and 0.221. Although it is not as large, it is still sizable for females, and is now significant at the one percent level in columns 1 and 2 . The estimates for males are again small and statistically insignificant. In estimates that were not sex-specific, Sandy and Duncan (1996) found private-school attendance increased log hourly earnings anywhere from 10 to 14 percent, depending on the model. The average of our estimates is somewhat similar.

Table 2: Relationship between Private-schooling Rates and Adult Log Annual Earnings

(1)

(2)

\section{$\underline{\text { A. Females }}$}

Cohort Private-school Enrollment Rate

$0.230 * *$

$0.239 * *$

$0.275 * *$

(0.097)

(0.108)

$\underline{\text { B. Males }}$

Cohort Private-school Enrollment Rate

$-0.081$

$-0.019$

$-0.017$

(0.078)

(0.080)

Birth-State Cohort Controls

No

Yes

Yes

State-Specific Time Tends

No

No

Yes

Notes: Standard errors in parentheses are clustered by birth state. All regressions include dummy variables for survey year, birth year, age, and birth state. The regression sample includes 1,539,809 individual observations for females and 1,710,699 individual observations for males. **Significant at 5 percent level.

(C) Southern Regional Science Association 2016. 
Table 3: Relationship between Private-schooling Rates and Adult Log Hourly Earnings

\begin{tabular}{|c|c|c|c|}
\hline & $(1)$ & $(2)$ & $(3)$ \\
\hline \multicolumn{4}{|l|}{ A. Females } \\
\hline$\overline{\text { Cohort Private-school Enrollment Rate }}$ & $\begin{array}{c}0.187 * * * \\
(0.062)\end{array}$ & $\begin{array}{c}0.185 * * * \\
(0.067)\end{array}$ & $\begin{array}{c}0.221 * * \\
(0.088)\end{array}$ \\
\hline \multicolumn{4}{|l|}{ B. Males } \\
\hline Cohort Private-school Enrollment Rate & $\begin{array}{l}-0.057 \\
(0.065)\end{array}$ & $\begin{array}{c}-0.014 \\
(0.065)\end{array}$ & $\begin{array}{c}-0.002 \\
(0.089)\end{array}$ \\
\hline Birth-State Cohort Controls & No & Yes & Yes \\
\hline State-Specific Time Tends & No & No & Yes \\
\hline \multicolumn{4}{|c|}{$\begin{array}{l}\text { Notes: Standard errors in parentheses are clustered by birth state. All regressions include dummy variables for survey year, } \\
\text { birth year, age, and birth state. The regression sample includes 1,539,809 individual observations for females and 1,710,699 } \\
\text { individual observations for males. **Significant at } 5 \text { percent level; ***Significant at } 1 \text { percent level. }\end{array}$} \\
\hline \multicolumn{4}{|c|}{$\begin{array}{l}\text { In Tables } 4 \text { and } 5 \text {, we continue to see significant and reasonably large coefficients for females, } \\
\text { with and without progressively more detailed birth-state controls. Thus, part of the higher } \\
\text { earnings that women receive from private schooling likely occurs through increased years of } \\
\text { schooling and access to higher-earning occupations. For all four of our dependent variables, } \\
\text { we found no statistically significant influence of private school for males. Results for males } \\
\text { ranged from small and positive to small and negative. }\end{array}$} \\
\hline
\end{tabular}

Table 4: Relationship between Private-schooling Rates and Years of Schooling

\begin{tabular}{lccc}
\hline \hline & $(1)$ & $(2)$ & $(3)$ \\
\hline A. Females & & & \\
Cohort Private-school Enrollment Rate & $0.465^{* *}$ & $0.522^{* *}$ & $0.882^{* * *}$ \\
& $(0.213)$ & $(0.203)$ & $(0.286)$ \\
B. Males & & & \\
Cohort Private-school Enrollment Rate & -0.094 & 0.087 & 0.439 \\
& $(0.217)$ & $(0.184)$ & $(0.303)$ \\
Birth-State Cohort Controls & & & \\
State-Specific Time Tends & No & Yes & Yes \\
\hline \hline
\end{tabular}

Notes: Standard errors in parentheses are clustered by birth state. All regressions include dummy variables for survey year, birth year, age, and birth state. The regression sample includes 1,539,809 individual observations for females and 1,710,699 individual observations for males. **Significant at 5 percent level; ***Significant at 1 percent level. 


\section{Table 5: Relationship between Private-schooling Rates and Occupation Earnings Score}

\begin{tabular}{lccc}
\hline \hline & $(1)$ & $(2)$ & $(3)$ \\
\hline A. Females & & & \\
Cohort Private-school Enrollment Rate & $6.487^{*}$ & $6.924^{* *}$ & $8.905^{*}$ \\
& $(3.351)$ & $(3.432)$ & $(5.252)$ \\
& & & \\
B. Males & & & \\
Cohort Private-school Enrollment Rate & 13.773 & 8.431 & -9.734 \\
& $(8.454)$ & $(8.313)$ & $(13.416)$ \\
Birth-State Cohort Controls & & & \\
State-Specific Time Tends & No & Yes & Yes \\
\hline \hline
\end{tabular}

Notes: Standard errors in parentheses are clustered by birth state. All regressions include dummy variables for survey year, birth year, age, and birth state. The regression sample includes 1,539,809 individual observations for females and 1,710,699 individual observations for males. *Significant at 10 percent level; **Significant at 5 percent level.

\section{DISCUSSION AND CONCLUSION}

The purpose of this paper was to examine the possible benefits that private schooling may provide to individuals in the job market. We have reviewed the literature on the subject, and while there are differing opinions, the majority of the literature points to there being some benefit from private schooling. This paper is unique because it examines state and year-of-birth cohorts over a period of time to measure the benefits and also because it includes four dependent variables including wages, higher educational attainment, and job types. The cohort-level approach we use provides a different perspective than individual-level approaches used in previous literature and reduces concerns about endogeneity due to unobserved individual heterogeneity. We isolated the effects of private schooling as much as possible by controlling for birth-state fixed effects, as well as other expected determinants of having a high-paying career, such as parental income and education. Additionally, our cohorts are limited to non-Hispanic whites, which makes the results less likely to be influenced by other factors associated with race and ethnicity.

Guided by previous literature (e.g. Sandy and Duncan, 1996; Kim, 2011; Neal, 1997), we hypothesized that there would be a positive effect of private schooling on our dependent variables. The results for females were consistent with this hypothesis and therefore not surprising. The results for males were, however, somewhat unexpected. There are a few potential reasons that could explain why there is no significant effect for males. One possibility is that private primary and secondary schooling may primarily provide advantages to those seeking jobs requiring medium-level educational skills, and men may especially sort into jobs requiring high or low education levels (Macpherson and Hirsch, 1995). Many jobs require good manual skills with only limited formal education, and a person with a good K-12 education ${ }^{13}$ might not be paid any more in a low-education job than someone with a relatively poor education. For higheducation jobs, the differentiating factors for success and higher income are likely cultivated

${ }^{13}$ Our use of the term K-12 education is common in the U.S. to refer to refer to kindergarten through 12 th grade.

(c) Southern Regional Science Association 2016. 
while obtaining many years of higher education, especially in graduate programs. By the time an individual reaches graduate level coursework, any advantage from having attended private school may be minimized. Still, those seeking medium-education jobs may be most likely to receive some benefit from a high-quality private K-12 education. This circumstance may affect females and males differently because males may be less likely to seek medium-education jobs. In low-education jobs, males are often rewarded and compensated for their physical abilities, so much so that it might be more beneficial to choose a low-education job over a medium-education one given their comparative advantage in the former (Altonji and Blank, 1999). Males are more likely to choose low-education, high-physicality jobs (such as construction) than females (Macpherson and Hirsch, 1995). If a significant proportion of males choose low-education jobs over medium-education jobs, it makes sense that many males might not benefit from a private education. This is also consistent with research findings that earnings increases from additional years of schooling are higher for females (Winters, 2015).

Another perspective is to consider why there is an effect for females, rather than why there is not one for males. A female who attends a private school might especially feel that her family has invested in her education, and then might choose to continue the investment by obtaining more higher education. Also, she might decide to pursue a higher-paying career because of the initial investment. Additionally, a female receiving a high quality education might choose to wait to start a family in favor of continuing her career (Clark and Del Bono, 2016). This could be consistent with a higher proportion of white females attending private school in urban areas compared to rural areas, where marriage and child rearing on average happens earlier in life. Additionally, female private-schooling benefits may result from specific aspects of the educational environment, such as increased confidence and leadership skills that might occur from attending completely or predominantly female schools (Billger, 2007). More generally, females may simply be more responsive to educational quality than males, especially in preparing to succeed in college (Deming et al., 2014). Better understanding the reasons for female gains has the potential to help improve education more broadly, including in the public sector.

The mixed findings by sex may also fundamentally depend on whether public schools are underserving students and whether private schools can actually do a better job. For example, it may be that public schools systematically underserve students of both sexes. Our results would then imply that private schools are less flawed in educating females but not males. Still, it may instead be that public schools adequately educate males but not females, while private schools adequately educate both sexes. Strong conclusions about the adequacy of public and private education do not follow directly from our study. The clearest implications are simply that males and females respond differently to public and private schooling with females benefiting from private schooling and males not.

Because this paper examines only non-Hispanic white cohorts for simplicity, it is unable to address whether non-whites might receive benefits from private schooling. In fact, other research suggests that non-whites receive very significant benefits from attending private school. In particular, Neal (1997) found that minorities in urban areas benefit greatly from Catholic secondary education, with Catholic school explaining a 23 percent increase in hourly wages. We explored using our cohort-level approach to examine possible effects of private schooling for blacks and Hispanics, but the results were noisy, inconsistent, and, therefore, hard to interpret. The synthetic cohort method we use is based on five percent samples of young people in 1980 
and 1990, which creates some amount of measurement error due to sampling in the privateschooling rates. Sampling error problems are exacerbated by small sample sizes as is the case for blacks and Hispanics in many small states. Birth-state fixed effects and other controls worsen measurement error problems related to small sample sizes because they explain away real variation in the data and leave remaining variation in the observed data that is largely due to noise and less due to signal (actual variation). Future research may be able to provide new techniques to apply cohort-level methods to examine the effects of private schooling on minority groups.

Our analysis is also potentially limited in other dimensions. For one, the data only allow cohorts to be tracked over time at the state level, but private-schooling options and attendance rates vary considerably across areas within states. Future studies may be able to use administrative data to improve on this limitation and instead track cohorts at lower geographic levels, e.g., counties or MSAs. Additionally, we are unable to pin down what is driving the variation in private-schooling rates across cohorts within states, creating concerns about possible endogeneity due to omitted variable bias. We contend that after including our detailed set of control variables, the remaining variation in private-schooling rates is likely to be largely random and, thus, will give accurate results, but we are unable to be certain on this. Future studies may be able to leverage administrative data with natural experiments creating exogenous variation in private-school attendance, perhaps at the cohort level or the individual level using lotteries or sharp discontinuities predicting treatment.

The significant positive effects for white females that we observe suggest that there are at least some benefits from attending private school. But these benefits do not accrue to white males. Ultimately, more research is needed to better understand the benefits of private schooling, specifically to examine who benefits, by how much, and why. At an individual level, specific circumstances likely affect what the most appropriate school choice is for a given student. Individuals learn best in different ways and in different settings, and differences by sex are not incredibly surprising ex post. Furthermore, some public schools indeed perform at very high levels, and some private schools may be of poor quality. While we cannot fully explain the causes, our results suggest that private schooling on average increases hourly earnings for white females by roughly 18 to 22 percent. This is an economically meaningful effect with important implications for public policy. Many areas have underperforming public schools and many students, especially females, may be better off if given the choice to attend private schools instead.

\section{REFERENCES}

Altonji, Joseph G. and Rebecca M. Blank. (1999) "Race and Gender in the Labor Market," in Orley Ashenfelter and David Card, eds., Handbook of Labor Economics, Volume 3. Elsevier: Amsterdam, pp. 3143-3259.

Altonji, Joseph G., Todd E. Elder, and Christopher R. Taber. (2005) "Selection on Observed and Unobserved Variables: Assessing the Effectiveness of Catholic Schools," Journal of Political Economy, 113, 151-184.

Billger, Sherrilyn M. (2007) "Does Attending Predominately-Female Schools Make a Difference? Labor Market Outcomes for Women," Journal of Economics and Finance, 31, 166-185.

(C) Southern Regional Science Association 2016. 
Bracey, Gerald W. (1996) "International Comparisons and the Condition of American Education," Educational Researcher, 25, 5-11.

Card, David and Alan B. Krueger. (1992) "Does School Quality Matter? Returns to Education and the Characteristics of Public Schools in the United States," Journal of Political Economy, 100, 1-40.

Cebula, Richard J., Franklin G. Mixon Jr, and Mark A. Montez. (2015) “Teachers' Salaries and Human Capital, and Their Effects on Academic Performance: An Institution-Level Analysis of Los Angeles County High Schools," Journal of Economics and Finance, 39, 347-356.

Chetty, Raj, John N. Friedman, and Jonah E. Rockoff. (2014) "Measuring the Impacts of Teachers II: Teacher Value-Added and Student Outcomes in Adulthood," American Economic Review, 104, 2633-2679.

Clark, Damon and Emilia Del Bono. (2016) "The Long-Run Effects of Attending an Elite School: Evidence from the United Kingdom," American Economic Journal: Applied Economics, 8, 150-176.

Coleman, James S. and Thomas Hoffer. (1987) Public and Private High Schools: The Impact of Communities. Basic Books: New York.

Coleman, James, Thomas Hoffer, and Sally Kilgore. (1982) "Cognitive Outcomes in Public and Private Schools," Sociology of Education, 55, 65-76.

Coughlin, Conor and Carolina Castilla. (2014) "The Effect of Private High School Education on the College Trajectory," Economics Letters, 125, 200-203.

Deming, David J., Justine S. Hastings, Thomas J. Kane, and Douglas O. Staiger. (2014) "School Choice, School Quality, and Postsecondary Attainment," American Economic Review, 104, 991-1013.

Dobbie, Will and Roland G. Fryer Jr. (2013) "Getting Beneath the Veil of Effective Schools: Evidence from New York City," American Economic Journal: Applied Economics, 5, 28-60.

Duncan, Kevin C. and Jonathan Sandy. (2007) "Explaining the Performance Gap between Public and Private School Students," Eastern Economic Journal, 33, 177-191.

Elder, Todd and Christopher Jepsen. (2014) "Are Catholic Primary Schools More Effective than Public Primary Schools?," Journal of Urban Economics, 80, 28-38.

Evans, William N. and Robert M. Schwab. (1995) "Finishing High School and Starting College: Do Catholic Schools Make a Difference?," Quarterly Journal of Economics, 110, 941974.

Gritsch, Martin. (2006) "Public vs. Private Schools: The Impact on Wage Rates," Journal of Economics and Economic Education Research, 7, 3-17.

Jackson, C. Kirabo, Rucker C. Johnson, and Claudia Persico. (2016) "The Effects of School Spending on Educational and Economic Outcomes: Evidence from School Finance Reforms," Quarterly Journal of Economics, 131, 157-218.

(C) Southern Regional Science Association 2016. 
Jha, Nikhil, and Cain Polidano. (2015) "Long-Run Effects of Catholic Schooling on Wages," The B.E. Journal of Economic Analysis \& Policy, 15, 2017-2045.

Kim, Young-Joo. (2011) "Catholic Schools or School Quality? The Effects of Catholic Schools on Labor Market Outcomes," Economics of Education Review, 30, 546-558.

Lee, Valerie E., Todd K. Chow-Hoy, David T. Burkam, Douglas Geverdt, and Becky A. Smerdon. (1998) "Sector Differences in High School Course Taking: A Private School or Catholic School Effect?," Sociology of Education, 71, 314-335.

Macpherson, David A. and Barry T. Hirsch. (1995) "Wages and Gender Composition: Why Do Women's Jobs Pay Less?," Journal of Labor Economics, 13, 426-471.

Neal, Derek. (1997) "The Effects of Catholic Secondary Schooling on Educational Achievement," Journal of Labor Economics, 15, 98-123.

Neal, Derek. (1998) "What Have We Learned about the Benefits of Private Schooling?," Economic Policy Review, 4, 79-86.

Peltzman, Sam. (1993) "The Political Economy of the Decline of American Public Education," Journal of Law and Economics, 36, 331-370.

Peterson, Paul E. and Elena Llaudet. (2006) "On the Public-Private School Achievement Debate," Harvard Kennedy School Working Papers, RWP06-036: Cambridge, Massachusetts.

Rouse, Cecilia E. (1998) "Private School Vouchers and Student Achievement: An Evaluation of the Milwaukee Parental Choice Program," Quarterly Journal of Economics, 113, 553602.

Ruggles, Stephen, Katie Genadek, Ronald Goeken, Josiah Grover, and Matthew Sobek. (2015) Integrated Public Use Microdata Series: Version 6.0. University of Minnesota.

Sandy, Jonathan and Kevin Duncan. (1996) "Does Private Education Increase Earnings?," Eastern Economic Journal, 22, 303-312.

Sass, Tim R., Ron W. Zimmer, Brian P. Gill, and T. Kevin Booker. (2016) "Charter High Schools' Effects on Long-Term Attainment and Earnings," Journal of Policy Analysis and Management, 35, 683-706.

Vella, Francis. (1999) "Do Catholic Schools Make a Difference? Evidence from Australia," Journal of Human Resources, 34, 208-224.

Winters, John V. (2015) "Estimating the Returns to Schooling Using Cohort-Level Maternal Education as an Instrument," Economics Letters, 126, 25-27.

Winters, Marcus A. and Jay P. Greene. (2007) "Debunking a Special Education Myth," Education Next, 7, 67-71.

Witte, John F. (1992) "Private School Versus Public School Achievement: Are There Findings that Should Affect the Educational Choice Debate?" Economics of Education Review, 11, 371-394.

(c) Southern Regional Science Association 2016. 